\title{
Effect of Temperature on Biohydrogen and Biomethane Productions by Anaerobic Digestion of Sugar Beet by-Products
}

\author{
K. Aboudi, X. Gómez-Quiroga, C. J. Álvarez-Gallego, J. M. Quiroga-Alonso, and L. I. Romero-García
}

\begin{abstract}
This work analyzes the effect of temperature on the anaerobic digestion of sugar beet by-products for both biohydrogen and biomethane production. The findings demonstrate that the anaerobic process was significantly affected by the increase in temperature from mesophilic to thermophilic or hyper-thermophilic conditions. Therefore, it was found that the mesophilic temperature was more suitable for the anaerobic digestion of sugar beet by-products, using either the raw feedstock or the pretreated feedstock at higher temperatures. The specific production of biohydrogen from thermophilic acidogenic digester was 1.7 fold higher than that obtained from the hyper-thermophilic one. Moreover, when raw feedstock was used in single stage digesters, a methane production rate of $0.55 \mathrm{LCH} 4 / \mathrm{Lr}^{*} \mathrm{~d}$ was obtained from the mesophilic digester, which was $45 \%$ higher than that of the thermophilic one. It has been observed that the increase in temperature led to a high accumulation of volatile and long chain fatty acids, inhibiting and slowing down the anaerobic process.
\end{abstract}

Index Terms-Anaerobic digestion, inhibition, sugar beet by-products, temperature.

\section{INTRODUCTION}

Anaerobic digestion (AD) is considered as an attractive technology for renewable energy production from different organic wastes [1]. Temperature plays an important role in biological processes such as the anaerobic digestion process [2]. Anaerobic digestion can be performed at psychrophilic $\left(25^{\circ} \mathrm{C}\right)$, mesophilic $\left(35^{\circ} \mathrm{C}\right)$, thermophilic $\left(55^{\circ} \mathrm{C}\right)$, and even higher temperatures, such as hyper-thermophilic $\left(65^{\circ} \mathrm{C}\right)$. In general, higher temperature conditions lead to higher metabolic rates. Thus, increasing the operating temperature increases the hydrolysis rate of complex organic waste, which can lead to a high generation of methane, since hydrolysis is commonly recognized as a limiting-step in the anaerobic process [3]. However, in some cases, working at higher temperatures can be counterproductive because increased rates of hydrolysis and acidogenesis can lead to an

Manuscript received July 10, 2017; revised October 10, 2017.

K. Aboudi, C. J. Álvarez-Gallego, and L. I. Romero-García are with the Department of Chemical Engineering and Food Technology, Faculty of Sciences, Campus de Puerto Real, University of Cádiz, Spain (e-mail: kaoutar.aboudi@uca.es, luisisidoro.romero@uca.es).

X. Gómez-Quiroga was with Department of Chemical Engineering and Food Technology, Faculty of Sciences, Campus de Puerto Real, University of Cádiz, Spain (e-mail: xiomara.gomez@uca.es).

J. M. Quiroga-Alonso is with the Department of Environmental Technology, Faculty of Marine and Environmental Sciences, Campus de Puerto Real. University of Cádiz, Spain (e-mail: josemaria.quiroga@uca.es). excessive release of inhibitory intermediates in the medium (i.e. volatile fatty acids, free ammonia, long chain fatty acids, furans [3], [4]), which negatively affects the whole process.

The use of temperature-phased (TPAD) or two-phase (TP) configurations for the $\mathrm{AD}$ process has shown to be efficient for some substrates, such as organic fraction of municipal solid waste [5], food waste [6] and sewage sludge [7]. The TP configuration allows the production of both biohydrogen and biomethane in two separate consecutive digesters (acidogenic and methanogenic), where the effluent from the acidogenic digester is used as feed for the methanogenic one. The TPAD configuration consists on the use of two digesters operating at different temperatures either for the production of biomethane or biohydrogen. Commonly, in the TPAD process, the first reactor operates at a higher temperature than the second one. In both configurations, the first stage can be considered as a previous pretreatment of the raw material for the second digester, which receives a suitable hydrolyzed material for the methanogenic microorganisms [8].

In this context, the aim of this study was, firstly, to compare the performance of two acidogenic digesters for biohydrogen production from SBB, operating at different temperatures (thermophilic and hyper-thermophilic). Moreover, the effluents from these acidogenic systems were used as a pretreated feedstock for two different mesophilic digesters. The results of these systems have also been compared to the single-stage AD of SBB without pretreatment, operating in both mesophilic and thermophilic conditions.

\section{MATERIAL AND METHODS}

\section{A. Substrate}

Sugar beet by-products consisted of dried pellets of exhausted pulp (85\%) mixed with molasses (15\%). This substrate was collected from the sugar production company "Azucarera" (AB-sugar group) located in southern of Spain. The raw SBB was used at a total solid content of $8 \%$ by rehydrating the pellets with deionized water 24 hours before of the daily feeding (once a day) [9].

\section{B. Semi-continuous Digesters Start-up Procedure}

Six semi-continuous stirred tank digesters with a $2.5 \mathrm{~L}$ working volume were used in this study. Digesters are made of stainless steel and are covered by a metal jacket for better heat transfer from a heating plate, located at the base of each digester, in order to maintain the temperature selected. Temperature was continuously monitored by an inner 
temperature sensor and controlled by a PID (Proportional-Integral-Derivative) control system. Each digester had an independent motor of agitation and a stirring blade [10].

To facilitate the discussion of results, Table I shows the nomenclature of each digester according to system configuration and temperature conditions. Fig. 1 depicts a schematic illustration of the experimental design for this study. Moreover, in Table II the physical-chemical characteristics of the raw SBB are given.

TABLE I: NOMENCLATURE OF THE DiGESTERS USED IN THIS STUDY

\begin{tabular}{|c|c|}
\hline Digesters & Temperature and Stage \\
\hline $\mathrm{Ac}-55^{\circ} \mathrm{C}$ & Thermophilic Acidogenic \\
\hline $\mathrm{Ac}-65^{\circ} \mathrm{C}$ & Hyper-thermophilic Acidogenic \\
\hline $\mathrm{SS}-55^{\circ} \mathrm{C}$ & Thermophilic Methanogenic Single Stage \\
\hline $\mathrm{SS}-35^{\circ} \mathrm{C}$ & Mesophilic Methanogenic Single Stage \\
\hline $\mathrm{TP}-55^{\circ} \mathrm{C}-35^{\circ} \mathrm{C}$ & $\begin{array}{l}\text { Thermophilic Acidogenic - Mesophilic } \\
\text { Methanogenic }\end{array}$ \\
\hline $\mathrm{TP}-65^{\circ} \mathrm{C}-35^{\circ} \mathrm{C}$ & $\begin{array}{l}\text { Hyper-thermophilic Acidogenic - Mesophilic } \\
\text { Methanogenic }\end{array}$ \\
\hline
\end{tabular}

TABLE II: CHARACTERISTICS OF SBB USED IN THIS STUDY

\begin{tabular}{|c|c|}
\hline Items & Values \\
\hline $\mathrm{pH}$ & $5.84 \pm 0.47$ \\
\hline Total Solids (\%) & $82.91 \pm 0.24$ \\
\hline Volatile Solids (\%TS) & $91.76 \pm 2.48$ \\
\hline Total - Chemical Oxygen Demand $\left(\mathrm{g} \mathrm{O}_{2} / \mathrm{kg}\right)^{*}$ & $154.84 \pm 13.57$ \\
\hline Soluble - Chemical Oxygen Demand $\left(\mathrm{g} \mathrm{O}_{2} / \mathrm{kg}\right)^{*}$ & $64.52 \pm 2.48$ \\
\hline Dissolved Organic Carbon (g C/kg) & $41.82 \pm 6.08$ \\
\hline Total Volatile Fatty Acidity (g HAc/kg) ${ }^{*}$ & $5.27 \pm 0.75$ \\
\hline Ammonia - Nitrogen (g N/kg) & $0.33 \pm 0.06$ \\
\hline Total Nitrogen (g N/kg) ${ }^{*}$ & $8.09 \pm 1.54$ \\
\hline Alkalinity $\left(\mathrm{gCaCO}_{3} / \mathrm{kg}\right)^{*}$ & $0.11 \pm 0.01$ \\
\hline
\end{tabular}

${ }^{*} \mathrm{~g} / \mathrm{kg}$ on wet basis.

\section{Analytical Parameters}

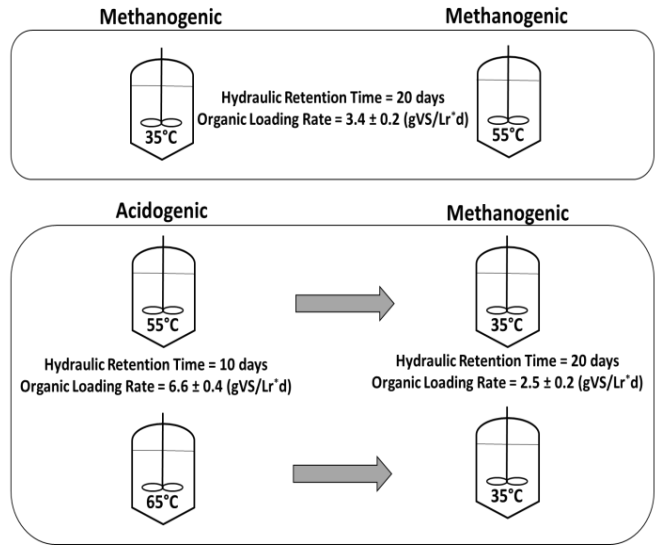

Fig. 1. Schematic illustration of the experimental design.

Standard Methods for the Examination of Water and Wastewater [11] were used to analyse the samples and effluents of all reactors. Samples of VFAs were analysed by using a gas chromatograph (Shimadzu ${ }^{\circledR}$ GC-2010) equipped with a flame ionization detector (FID) and a capillary column filled with Nukol® (diameter of $0.25 \mu \mathrm{m}$ and $30 \mathrm{~m}$ length). Biogas generated during the assays was collected in a $10 \mathrm{~L}$ Tedlar® gas bag (SKC) and its volume was measured daily using a high precision drum-type gas meter (Ritter® TG5). Composition of biogas $\left(\mathrm{H}_{2}, \mathrm{CH}_{4}, \mathrm{CO}_{2}\right)$ was determined by using a gas chromatograph (Shimadzu ${ }^{\circledR}$ GC-2010) with a stainless steel column packed with Carbosieve ${ }^{\circledR}$ SII (diameter of $3.2 \mathrm{~mm}$ and $3.0 \mathrm{~m}$ length) and a thermal conductivity detector (TCD).

\section{RESULTS AND DISCUSSION}

\section{A. Performance of Acidogenic Digesters}

The specific hydrogen productions obtained from thermophilic and hyper-thermophilic acidogenic digesters are shown in the Fig. 2. Both digesters started with similar hydrogen production rates. However, after around 20 days of operation, productions from the thermophilic digester significantly exceeds those of the hyper-thermophilic one, reaching a final production 1.7 fold higher.

Average daily hydrogen production rates (HPR) of acidogenic digesters were $0.45 \pm 0.15 \mathrm{LH}_{2} / \mathrm{L}_{\mathrm{r}}{ }^{*} \mathrm{~d}$ and $0.32 \pm$ $0.10 \mathrm{LH}_{2} / \mathrm{L}_{\mathrm{r}}{ }^{*} \mathrm{~d}$ for thermophilic and hyper-thermophilic conditions, respectively. These results were comparable with other findings in the literature. In [12], authors obtained a similar HPR from the dark fermentation of organic fraction of municipal solid wastes $\left(0.43 \mathrm{LH}_{2} / \mathrm{L}_{\mathrm{r}}{ }^{*} \mathrm{~d}\right.$ at HRT of 3 days and OLR $\left.16 \mathrm{gVS} / \mathrm{Lr}^{*} \mathrm{~d}\right)$. Nevertheless, the specific hydrogen production (SHP) was lower than that observed in the present research at similar temperature $\left(55^{\circ} \mathrm{C}\right)$.

The reference [13] compared thermophilic and hyper-thermophilic AD of food wastes for bio-hydrogen production at HRT of 15, 10, 5 and 3 days. Authors reported that the thermophilic temperature was more advantageous than the hyper-thermophilic one. Stable operations were observed at thermophilic conditions operating at the HRT of 10 days. However, the higher SHP of $70.7 \mathrm{ml} \mathrm{H}_{2} / \mathrm{gVS}_{\text {fed }}$ and hydrogen content in the biogas $(58.6 \%)$ were obtained at the HRT of 5 days.

The organic matter degradation trough hydrolysis and acidogenesis steps produces, together with hydrogen, intermediates compounds mainly as volatile fatty acids (VFAs). Moreover, acidification is strictly related to the substrate characteristics. Hence, in [14] it was studied the suitability of the TPAD process for different kind of substrates, including sugar beet (SB). Authors found that SB had a high sugar content and led to a higher acidification $(\mathrm{pH}$ drop) and hence, a high hydrogen production. Similarly, [15] studied the effect of operational parameters (HRT, OLR, pH) on the enhancement of acidification from sugar beet wastes (wastewater and pulp) and reported that the increase of sugar beet pulp in the mixture with lower HRT operation conditions led to a high acidification of the digester, as a result of the increase in VFAs generation from this substrate.

The total volatile fatty acidity (TVFA) and the different VFAs generated in acidogenic digesters are shown in Fig. 3 (a) and (b), respectively for thermophilic and hyper-thermophilic digesters. 


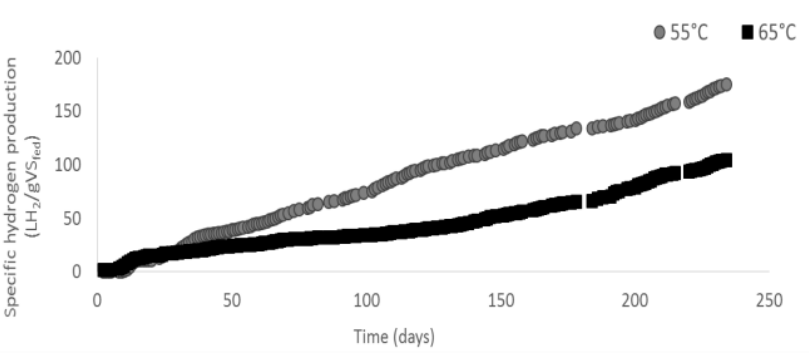

Fig. 2. Specific hydrogen productions from acidogenic digesters.
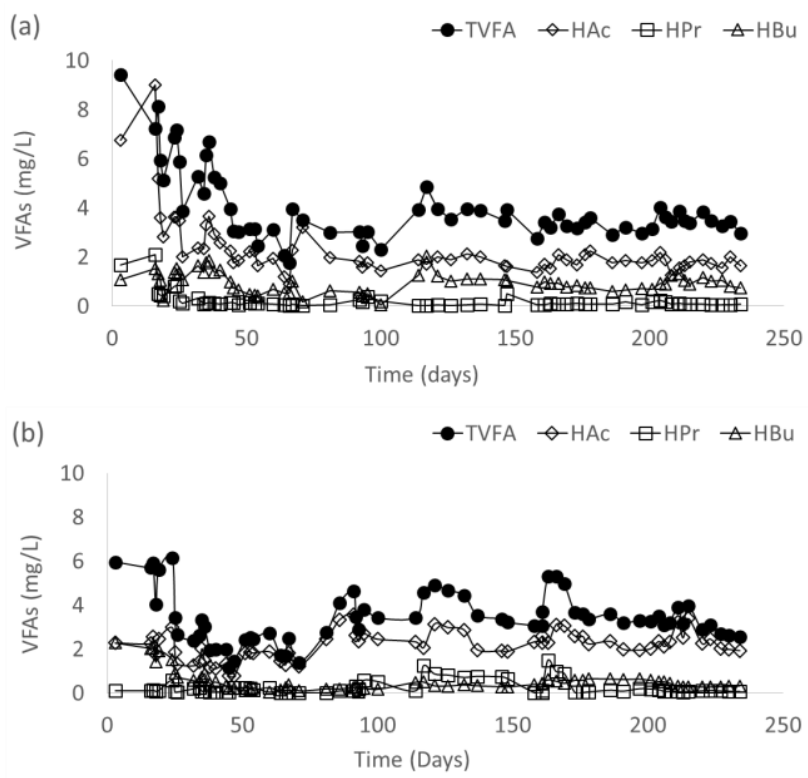

Fig. 3. Evolution of TVFA and the main VFAs in acidogenic digesters; (a) thermophilic and (b) hyper-thermophilic.

(a)

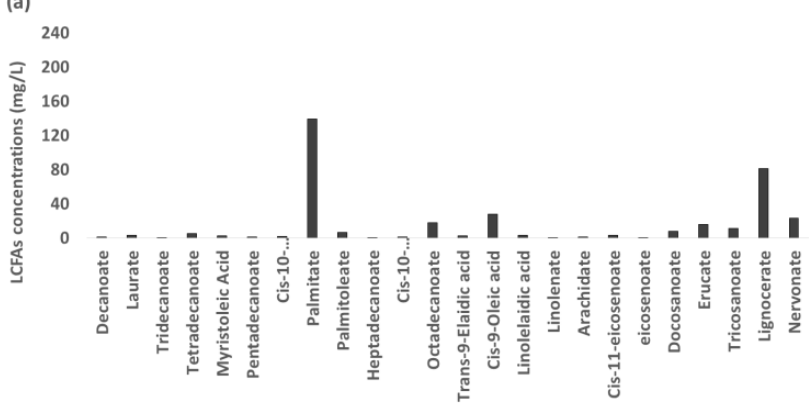

(b)

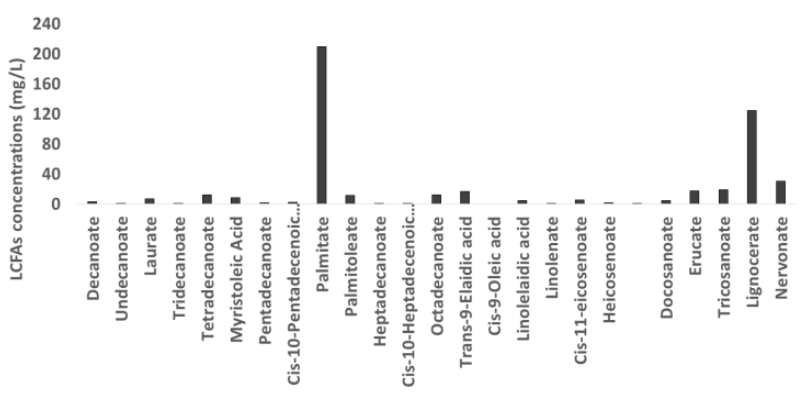

Fig. 4. Long chain fatty acids in acidogenic digesters; (a) thermophilic and (b) hyper-thermophilic.

In both digesters, the predominant VFAs were acetic acid (HAc), butyric acid (HBu) and propionic acid (HPr). The TVFA evolution started with high values and fluctuations due to microorganisms adaptation to the SBB substrate. After few days of operation, TVFA reached stable values around 4 $\mathrm{g} / \mathrm{L}$ at both temperature conditions, which is similar to the levels observed by others authors in an acidogenic digester for the treatment of vegetable wastes [16]. Based on individual organic acids profiles, their accumulations can be given mainly as acetic followed by butyric and propionic acids. These results agree with other investigations in acidogenic systems [16]. The highest HAc concentrations were observed at the higher temperature of $65^{\circ} \mathrm{C}$. In both digesters and due to acidification, $\mathrm{pH}$ correction with an alkali (potassium carbonate) has been necessary when the $\mathrm{pH}$ dropped below 5.5. Among the intermediates compounds of the anaerobic digestion process, long chain fatty acids (LCFAs) could be found. It should be noted that LCFAs present an inhibitory effect on the process, particularly for methanogens and acetogens [17], [18]. Fig. 4 shows the main LCFAs found in effluents from thermophilic (a) and hyper-thermophilic (b) acidogenic digesters. The results indicate that higher concentrations were observed at higher temperature conditions $\left(65^{\circ} \mathrm{C}\right)$. In both digesters, palmitate and lignocerate were predominants.

\section{B. Performance of Methanogenic Digesters}

The specific methane productions from single stage reactors and combined TPAD and TP processes are depicted in the Fig. 5.

Thermophilic single stage digester shows the lowest methane productions. In addition, a very slow starting-up of the process was observed for thermophilic reactor. The single stage mesophilic digester showed the highest final SMP, followed by $\operatorname{TPAD}^{\circ} 5^{\circ} \mathrm{C}-35^{\circ} \mathrm{C}$ and $\operatorname{TPAD} 65^{\circ} \mathrm{C}-35^{\circ} \mathrm{C}$. It has been observed that mesophilic temperature is more suitable for methane generation from SBB, regardless the system configuration. Therefore, despite of the high acetate content of effluents from acidogenic digesters and the presence of LCFAs, which are known to inhibit acetogenic methanogens, mesophilic digesters in the combined configurations were able to convert VFAs into methane. The lower methane generation in $\mathrm{SS}-55^{\circ} \mathrm{C}$ was related to further accumulation of acetate as shown in Fig. 6. The TVFA observed in the $\mathrm{SS}-55^{\circ} \mathrm{C}$ was even higher than the observed previously in acidogenic thermophilic digester, with also very high acetic acid accumulation. Moreover, propionic acid was also found at higher concentrations. Propionic acid has been largely reported to inhibit methanogens [4]. Both acetate and propionate accumulations could explain the lower methane generation at single stage thermophilic digester. Therefore, mesophilic temperature conditions showed better process performance in separate digesters or by using single stage configuration.

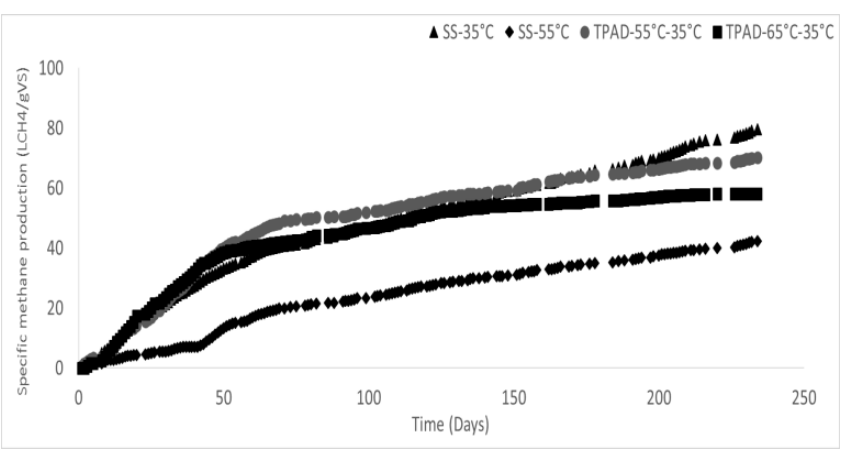

Fig. 5. Specific methane productions in methanogenic digesters. 


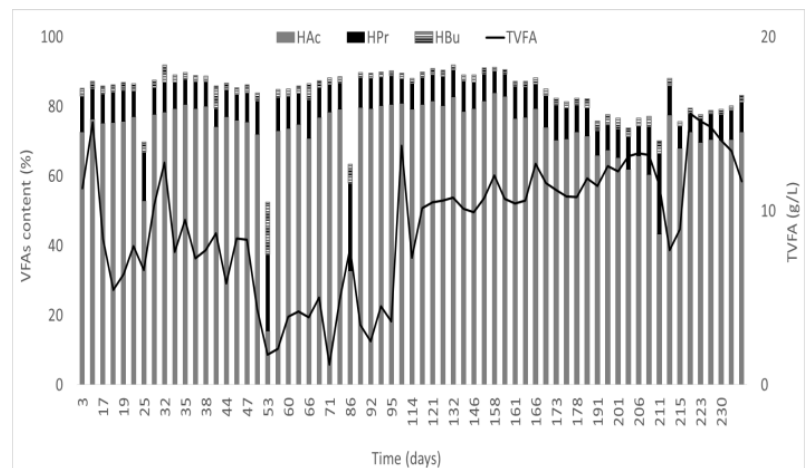

Fig. 6. TVFA and individual VFAs contents in SS thermophilic digester.

Table III summarizes the final performance of the methanogenic digesters. The higher volatile solids removal was observed in $\mathrm{SS}-35^{\circ} \mathrm{C}$, as a consequence of the best performance for the organic matter degradation and conversion into methane. Otherwise, the total solids destructions were higher in $\mathrm{TP}-55^{\circ} \mathrm{C}-35^{\circ} \mathrm{C}$ and $\mathrm{TP}-65^{\circ} \mathrm{C}-35^{\circ} \mathrm{C}$ due to that the feedstock was already hydrolysed in the first acidogenic digesters.

TABLE III: FINAL PERFORMANCE AND EFFLUENT QUALITY OF ALL METHANOGENIC DigeSTERS FOR THE STEADY STATE PERIOD

\begin{tabular}{|c|c|c|c|c|}
\hline Parameters & $\begin{array}{l}\mathrm{SS} \\
35^{\circ} \mathrm{C}\end{array}$ & $\begin{array}{l}\mathrm{SS} \\
55^{\circ} \mathrm{C}\end{array}$ & $\begin{array}{l}\mathrm{TP} \\
55^{\circ} \mathrm{C}-35^{\circ} \mathrm{C}\end{array}$ & $\begin{array}{l}\mathrm{TP} \\
65^{\circ} \mathrm{C}-35^{\circ} \mathrm{C}\end{array}$ \\
\hline $\mathrm{pH}$ & $7-7.8$ & $7.5-8$ & $7.5-8$ & $7.5-8.5$ \\
\hline TVFA $(\mathrm{g} / \mathrm{L})$ & $8.9 \pm 1.4$ & $11.7 \pm 1.7$ & $9.7 \pm 1.5$ & $28.5 \pm 6.3$ \\
\hline $\mathrm{HPr} / \mathrm{HAc}$ & $0.3 \pm 0.2$ & $0.2 \pm 0.1$ & $0.3 \pm 0.1$ & $0.3 \pm 0.1$ \\
\hline $\mathrm{HBu} / \mathrm{HAC}$ & $0.2 \pm 0.1$ & $0.2 \pm 0.1$ & $0.1 \pm 0.1$ & $0.1 \pm 0.1$ \\
\hline TVFA/alkalinity & $0.1 \pm 0.1$ & $0.1 \pm 0.1$ & $0.1 \pm 0.1$ & $0.2 \pm 0.1$ \\
\hline $\begin{array}{l}\mathrm{SMP} \\
\left(\mathrm{mLCH}_{4} / \mathrm{gVS}_{\mathrm{fed}}\right)\end{array}$ & $166.6 \pm 39.1$ & $90.3 \pm 17.1$ & $97.7 \pm 15.5$ & $41.7 \pm 12.1$ \\
\hline $\operatorname{MPR}\left(\mathrm{LCH}_{4} / \mathrm{L}_{\mathrm{r}}^{*} \mathrm{~d}\right)$ & $0.5 \pm 0,3$ & $0.3 \pm 0.1$ & $0.2 \pm 0.2$ & - \\
\hline $\mathrm{CH}_{4}(\%)$ & $56.7 \pm 10.1$ & $68.2 \pm 12.8$ & $55.9 \pm 9.8$ & $59.4 \pm 3.6$ \\
\hline $\mathrm{CO}_{2}(\%)$ & $43.1 \pm 10.5$ & $31.8 \pm 12.1$ & $44.1 \pm 7.7$ & $40.6 \pm 5.1$ \\
\hline VS removal $(\%)$ & $83.1 \pm 9.6$ & $65.8 \pm 7.5$ & $\begin{array}{l}69.7 \pm \\
11.5\end{array}$ & $72.1 \pm 7.6$ \\
\hline TS removal (\%) & $50.8 \pm 5.7$ & $51.2 \pm 4.3$ & $58.5 \pm 7.4$ & $53.9 \pm 5.3$ \\
\hline
\end{tabular}

\section{CONCLUSION}

The temperature increase has a detrimental effect on the anaerobic digestion of sugar beet by-products for both biohydrogen and biomethane production. The findings of this study demonstrate that the operation at high temperature conditions led to volatile and long chain fatty acids accumulation, thus inhibiting and slowing down the anaerobic process. From the obtained results, it could be concluded that the use of separated phases for the anaerobic digestion of sugar beet by-products was not necessary either.

\section{ACKNOWLEDGMENTS}

This research was supported by the projects CTM2013-43938-R and UNCA08-1E-035 (Spanish Ministry of Science and Innovation) and CTM2016-79071-R (Spanish Ministry of Economy, Industry and Competitiveness) and financed by the Spanish State Research Agency (“Agencia Estatal de Investigación”- AEI), and by the European Regional Development Fund (ERDF). Authors gratefully acknowledge the University of Cadiz (Spain) for the Scholarship UCA-2010-063PU/EPIF-FPI-A/BC.

\section{REFERENCES}

[1] C. Mao, Y. Feng, X. Wang, and G. Ren, "Review on research achievements of biogas from anaerobic digestion," Renewable and Sustainable Energy Reviews, vol. 45, 2015, pp. 540-555.

[2] M. A. Khan, H. H. Ngo, W. S. Guo, Y. Liu, L. D. Nghiem, F. I. Hai, L. J. Deng, J. Wang, and Y. Wu," Optimization of process parameters for production of volatile fatty acid, biohydrogen and methane from anaerobic digestion," Bioresource Technology, vol. 219, 2016, pp. 738-748.

[3] D. Yu, J. M. Kurola, K. Lähde, M. Kymäläinen, A. Sinkkonen, and M. Romantschuk, "Biogas production and methanogenic archaeal community in mesophilic and thermophilic anaerobic co-digestion processes," Journal of Environmental Management, vol. 143, 2014, pp. 54-60.

[4] Y. Chen, J. J. Cheng, and K. S. Creamer, "Inhibition of anaerobic digestion process: A review," Bioresource Technology, vol. 99, 2008, pp. 4044-4064.

[5] J. Fernández-Rodríguez, M. Pérez, and L. I. Romero, "Temperature-phased anaerobic digestion of industrial organic fraction of municipal solid waste: A batch study," Chemical Engineering Journal, vol. 270, 2015, pp. 597-604.

[6] R. Angeriz-Campoy, C. J. Álvarez-Gallego, and L. I. Romero-García, "Thermophilic anaerobic co-digestion of organic fraction of municipal solid waste (OFMSW) with food waste (FW): Enhancement of bio-hydrogen production," Bioresource Technology, vol. 194, 2015, pp. 291-296.

[7] R. M. Alonso et al., "Thermophilic and mesophilic temperature phase anaerobic co-digestion (TPAcD) compared with single-stage co-digestion of sewage sludge and sugar beet pulp lixiviation," Biomass and Bioenergy, vol. 93, 2016, pp. 107-115.

[8] H. Carrere, G. Antonopoulou, R. Affes, F. Passos, A. Battimelli, G. Lyberatos, and I. Ferrer, "Review of feedstock pretreatment strategies for improved anaerobic digestion: From lab-scale research to full-scale application," Bioresource Technology, vol. 199, 2016, pp. 386-397.

[9] K. Aboudi, C. J. Álvarez-Gallego, and L. I. Romero-García, "Influence of total solids concentration on the anaerobic co-digestion of sugar beet by-products and livestock manures," Science of The Total Environment, vol. 586, 2017, pp. 438-445.

[10] K. Aboudi, C. J. Álvarez-Gallego, and L. I. Romero-García, "Influence of total solids concentration on the anaerobic co-digestion of sugar beet by-products and livestock manures," Science of the Total Environment, vol. 586, 2017

[11] APHA-AWWA, Standards Methods for the Examination of Water and Wastewater, American Public Health Association Washington DC, USA, 2005

[12] S. Zahedi, R. Solera, F. Micolucci, C. Cavinato, and D. Bolzonella, "Changes in microbial community during hydrogen and methane production in two-stage thermophilic anaerobic co-digestion process from biowaste," Waste Management, vol. 49, 2016, pp. 40-46.

[13] D. E. Algapani, W. Qiao, M. Su, F. Pumpo, S. M. Wandera, F. Adani, and R. Dong, "Bio-hydrolysis and bio-hydrogen production from food waste by thermophilic and hyperthermophilic anaerobic process," Bioresource Technology, vol. 216, 2016, pp. 768-777.

[14] J. Lindner, S. Zielonka, H. Oechsner, and A. Lemmer, "Is the continuous two-stage anaerobic digestion process well suited for all substrates?" Bioresource Technology, vol. 200, 2016, pp. 470-476.

[15] E. Alkaya and G. N. Demirer, "Anaerobic acidification of sugar-beet processing wastes: Effect of operational parameters," Biomass and Bioenergy, vol. 35, 2011, pp. 32-39.

[16] Z. Zuo, S. Wu, W. Zhang, and R. Dong, "Performance of two-stage vegetable waste anaerobic digestion depending on varying recirculation rates," Bioresource Technology, vol. 162, 2014, pp. 266-272.

[17] R. M. Ziels, D. A. C. Beck, and H. D. Stensel, "Long-chain fatty acid feeding frequency in anaerobic codigestion impacts syntrophic community structure and biokinetics," Water Research, vol. 117, 2017, pp. 218-229.

[18] Ž. Zonta, M. M. Alves, X. Flotats, and J. Palatsi, "Modelling inhibitory effects of long chain fatty acids in the anaerobic digestion process," Water Research, vol. 47, 2013, pp. 1369-1380. 


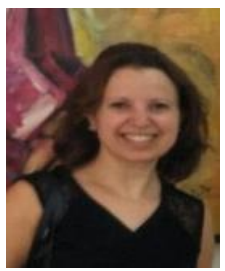

Kaoutar Aboudi was born in Morocco on June $12^{\text {th }}$ 1982 and she was graduated in environmental technology in 2006 from the University of Abdelmalek Essaîdi in Tangier, Morocco. She obtained his master in integral water management in 2009 from the University of Cádiz (Spain), where she also obtained his a PhD in the anaerobic digestion field in 2015. In 2014, she had a short research internship at the Delft University of Technology in Delft, the Netherlands. She published six peer-reviewed papers (JCR) as the first author and one peer-reviewed paper as a second author. She is a co-author of two international patents and she participated in nine international congresses.

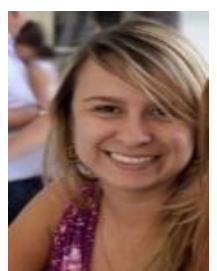

Xiomara Gómez Quiroga was born in Bucaramanga Colombia in 1983. She is an environmental engineer from the University of Santander in Colombia. She obtained his master in integral water management, 2012 from the University of Cádiz, (Spain). She is currently a $\mathrm{PhD}$ student in agri-food resources, at the Department of Chemical Engineering and Food Technology of the University of Cádiz (Spain). She has a teaching experience at the University of Santander (Colombia), 2014. She worked as consultant in elaboration of environmental studies and advisor of services for the implementation of environmental management system (Colombia)

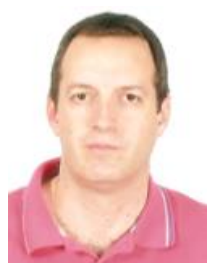

Carlos J. Álvarez-Gallego was born in Cádiz (Spain) on April $14^{\text {th }}, 1973$ and was graduated in chemical sciences (1996) and PhD in chemical engineering (2005) in the University of Cádiz (Spain). His professional career has been always linked to the University of Cádiz. First at all, he was predoctoral fellowship and he reached a teaching position as assistant professor in 2000, lecturer in 2006 and associated professor since 2012 till nowadays. This career has been developed in the Chemical Engineering and Food Technology Department of the University of Cádiz where he is the actual Secretary. He is author of numerous publications (it could be looked up in SCOPUS: Author ID: 36344605600) focused in the field of anaerobic treatments of wastes and wastewaters. Additionally, he is coauthor of the volumes I.3 and II.2 of the encyclopedia: From waste to resource, the way to sustainability (Madrid, Spain). Mundiprensa Ed., 2015 (ISBN 978-84-8476-702-2 and 978-84-8476-700-8). His past and actual research topics have covered aerobic composting, anaerobic digestion, methane and bio-hydrogen production and related ones.

Dr. Álvarez-Gallego is editor in waste management in agroecosystems, as part of the journal frontiers in sustainable food and agriculture.

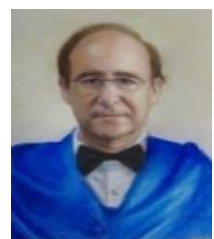

José María Quiroga Alonso was born in Cáceres (SPAIN), 1955. He graduate chemical science and Ph.D. in chemical (1985) in Cádiz University, Spain. José María is full professor of environmental technology in Dept. Envoronmental Technology in Cádiz University. Has been director of the Department Chemical Engineering (2004-2008), director of the Department Environmental Technology (2008-2012) and dean of Faculty of Marine and Environmental Science (2012-2016). José María Quiroga is full professor of environmental technology at the University Cádiz. He graduated from the University of Cádiz, he was Ph.D. at the University of Cádiz in 1985. Dr. Quiroga has the following teaching activities: courses for graduated students and ph.D. students in Environmental Engineering and Environmental Contamination. He has directed 20 Ph.d. thesis in subjects related to engineering and environmental pollution. Dr. Quiroga he has conducted the following research activities: Principal investigator/partner of several international and national research projects. He is author/coauthor of 200 papers published in international and national peer reviewed journals. Coauthor of one book and coautor different chapters of different books.

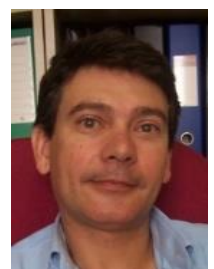

Luis I. Romero-García was born in Cádiz on December $18^{\text {th }}, 1960$ and he was graduated in chemical sciences in 1982, obtaining a $\mathrm{PhD}$ in chemical sciences in 1991 at the University of Cádiz (Spain). In January 1984, he earned a research fellowship, financed by the Spanish Ministry of Education, to conduct his doctoral studies. Later, in 1988, he reached a position as High School Professor of Physics and Chemistry. In 1993, he got a position as professor of chemical engineering at the University of Cádiz. Finally, since 2010, he holds a position of full professor of chemical engineering at the Department of Chemical Engineering and Food Technology of the University of Cádiz (Spain). He is co-author of more than 100 papers, most of them published in high impact factor journals (http://orcid.org/0000-0001-5193-7600). In addition, he is co-author of 28 books or book chapters, more than 150 communications in congresses and 7 international patents. The main topics of interest in his research career have been related to energy production (bio-hydrogen and bio-methane) from wastes by anaerobic processes. Currently, he is engaged in the study of polyhydroxialcanoates (PHAs) production from volatile fatty acids (VFAs) generated by dark fermentation.

Prof. Romero-García has been involved in more than 50 Research Projects, being responsible for 14 of them. He has frequently acted as reviewer for more than 17 high impact factor journals. In addition, he is a regular evaluator of research projects for different national and international agencies and he has been a member of the National Project Evaluation Commission of the Spanish Plan for Research, Development and Innovation. 